Faculdade de Ciências Econômicas UFRGS
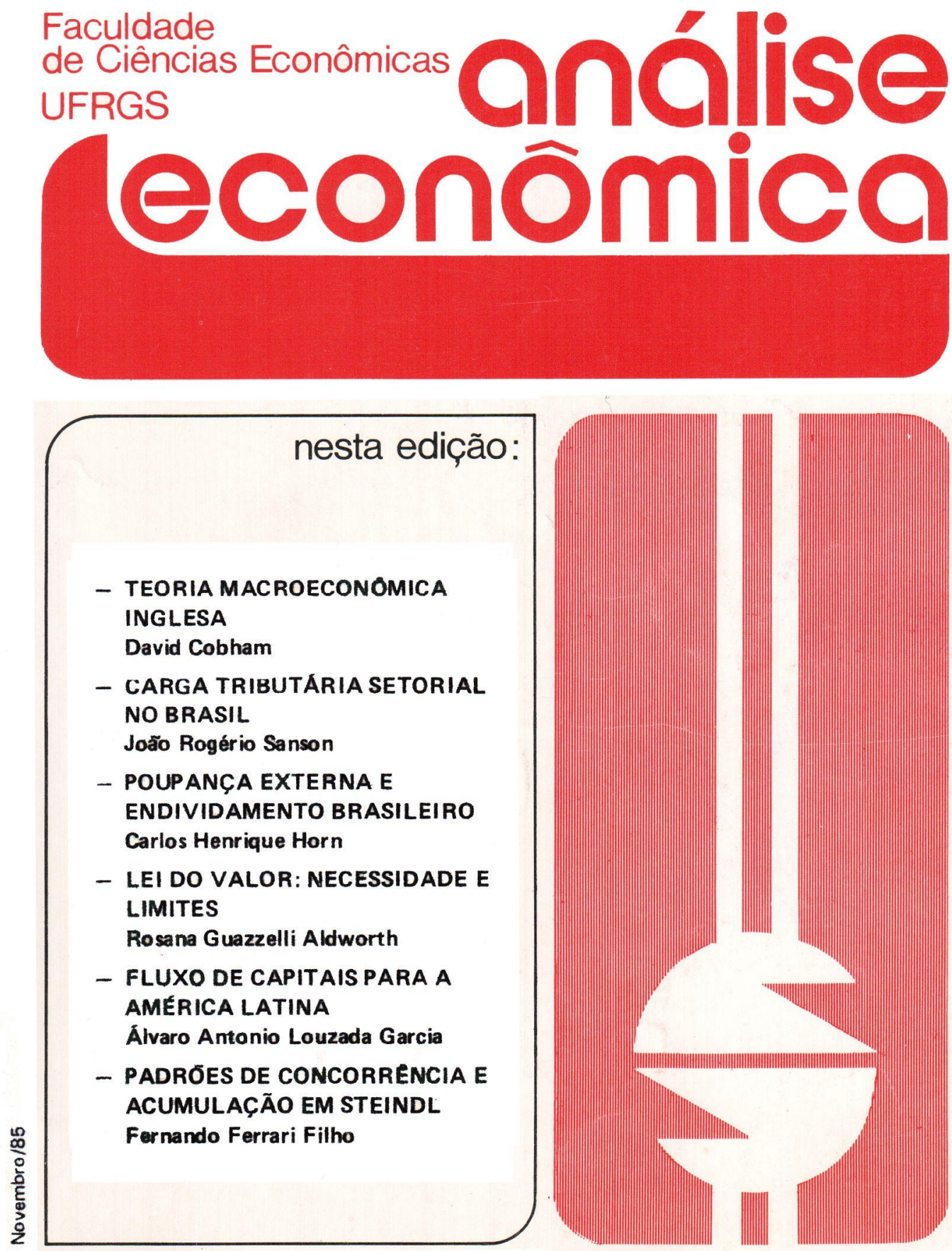

ano 3 
REITOR:Prof. Francisco Ferraz

DIRETOR DA FACULDADE DE CIÊNCIAS ECONÓMICAS:

Prof. Edgar lrio Simm

VICE-DIRETOR: Prof. Walter Meucci Nique

CHEFE DO DEPARTAMENTO DE CIENCIAS ECONOMICAS:

Prof. Renato Batista Masina

CONSELHO EDITORIAL: Prof. Pedro Cezar Dutra Fonsecs (Presidente)

Prof. Achyles Barcelos da Costa

Prof. Carlos Augusto Crusius

Prof. Claudio Francisco Accurso

Prof. Edgar Augusto Lanzer

Prof. Ernani Hickmann

Prof. Juvir Mattuella

Prof. João Rogério Sonson

Profa. Maria Imilda da Costa e Silva

Prof. Nali de Jesus de Souza

Prof. Nuno Renan L. de Figueiredo Pinto

Profa. Otilia Beatriz Kroeff Carrion

Prof. Paulo Alexandre Sphor

Prof. Roberto Camps Moraes

Profa。 Yeda Rorato Crusius

FUNDADOR: Prof. Antonio Carlos Santos Rosa

ANÁLISE ECONÔMICA publica dois números anuais nos meses de março e novembro. O preço da assinatura para 1986 é $\mathrm{Cr} \$ 20,000,00$, a ser pago através de cheque nominal para "Faculdade de Ciências Econômicas - UFRGS". Aceita-se permuta com revistas congêneres. Aceitam-se, também, livros para elaboração de resenhas ou recensões.

Toda a correspondência, material para publicação, assinaturas e permutas devem ser dirigidas a:

Prof. PEDRO CEZAR DUTRA FONSECA

Revista Análise Econômica

Avenida João Pessoa, $52-39$ andar

90.000 - Porto Alegre (RS) - Brasil 


\title{
ENSAIO SOBRE A NECESSIDADE E OS LIMITES DA LEI DO VALOR
}

\author{
ROSANA GUAZZELL! ALDWORTH*
}

\section{1 - INTRODUÇĀO}

O propósito na elaboração do presente trabalho é discutir a questão do valor enquanto regulador da via econômica, e avaliar em que medida é capaz de explicar e determinar o equilíbrio ou o movimento de todo o sistema econômico. Estudar o valor enquanto produto da atividade humana, como expressão da produçäo social e de relações entre os homens. Isto é, como resultado do trabalho humano.

A economia para Marx não trata de objetos e sim de relações entre as pessoas, e, em última instância, entre as classes sociais, apesar de parecerem relações entre objetos: o fetiche das mercadorias que encobre a sua natureza e ofusca as relações sociais. Neste sentido procura demonstrar e revelar a própria essência do capitalismo: a exploração do trabalho, a busca incessante da acumulação e do lucro, partindo da simplicidade da mercadoria à complexidade do capital. Dentro desta lógica do valor é que se baseia este trabalho (partindo do valor da mercadoria à própria regulação do capital).

"O valor não deve ser entendido como realidade estática. Sobretudo é no movimento que ele se manifesta, é movendo-se que se pode entendê-lo. É no movimento que ele se expressa." 1

\footnotetext{
* Em fase de elaboração de Dissertação de Mestrado no Curso de Pós-Graduação em Eco nomia do IEPE/UFRGS.

1 - PAULA, João Antônio de. "Ensaio sobre a atualidade da lei do valor". In: Revista de Economia Política, São Paulo, Brasiliense, Vol. 4, nọ 2, abril-junho de 1984, p. 128.

\begin{tabular}{|l|l|l|l|l|}
\hline ANÁLISE ECONÓMICA & ANO 3 & Nọ 5 & NOV/85 & p. 53-69 \\
\hline
\end{tabular}
}


Portanto, partindo desta perspectiva é que se coloca a necessidade de um embasamento histórico, de um movimento no tempo que nos mostre a realidade do desenvolvinento histórico. 0 próprio método de Marx pretende investigar as leis dialéticas da evolução e tanto as condições da existência do capitalismo como também seus limites históricos. Tendo isto em vista, pretende-se mostrar como, historicamente, se apresenta o problema do excedente e as diferentes formas de sua apropriação, o que leva à necessida. de da formulação da lei do valor-trabalho, tornando a exploração, que se esconde sob a máscara da troca, visível.

Mas quais os limites da vigência da lei do valor? Isto também pretende-se examinar, tanto dentro do próprio sistema capitalista como no sistema socialista, resultado de mais um movimento histórico importante.

Finalmente, em que sentido a própria lei do valor cria as condições para o seu bloqueio e sua destruição? E que conclusões podemos tirar desta resposta?

\section{2 - PERSPECTIVAS HISTORICAS}

Esta análise histórica pretende privilegiar as condições materiais de produção e reprodução da via social, em diferentes modos de produção capitalista, no sentido de revelar as relações entre os indivíduos como produtores e as condições materiais de sua existência, os meios de produção, as condições de produção do sobreproduto ou excedente, e o destino desse sobreproduto.

Começando pelas comunidades antigas, pode-se dizer que estas se caracterizavam pela posse coletiva da terra, principal meio de produção que possibilitava a sobrevivência da coletividade e de seus membros. $\mathrm{O}$ indivíduo está em contato direto com a terra, sendo que uma parte de sua produção cabe à comunidade, que exatamente garante o seu trabalho na terra, destinado a fins coletivos. Temos, portanto, já aqui, uma divisão do trabalho: uma parte é o trabalho necessário para o seu sustento e de sua familia, outra é transferida para a comunidade: a parte do sobretrabalho. Esta transferência do sobreproduto para a comunidade é exatamente a garantia de sua sobrevivência e da própria coletividade, que the garante o uso dos meios de produção, não sendo portanto o resultado de nenhum tipo de coerção ou violência. 
O modo de produção escravista faz do trabalhador, o escravo, a essência de sua forma de produção e, neste caso, é explícita a maneira de apropriação do excedente: através da apropriação da própria liberdade do indivíduo e com o respaldo jurídico-institucional.

Na sociedade feudal, a relação entre os indivíduos se caracteriza basicamente pelo fato de alguns (senhores feudais) deterem a propriedade da terra, que portanto se individualiza; enquanto que outros (servos, camponeses), que não têm a propriedade da terra, trabalham diretamente nela, estando portanto de posse de seus meios de produção, o que os capacita a viver de seu próprio trabalho, em troca de um pagamento ao senhor feudal, que pode se dar, como veremos, de várias formas. A transferência do sobreproduto para o senhor feudal é o resultado da relação de poder que este exerce, dado o seu direito de propriedade, e se manifesta abertamente através da coerção e da violência, respaldadas pela lei. Perante a lei os indivíduos são diferentes e como tal tèm direitos e deveres diversos. Portanto a pressão exercida para realizar a apropriação do excedente econômico se dá, no âmbito social, cultural e jurídico, como um ato de arbítrio e não no âmbito econômico.

A servidão que está explícita no feudalismo impõe ao produtor a satisfação de uma exigência do senhor feutal, isto é, a criação de um sobreproduto, e, é claro, a sua transferência para o senhor. Esta transferência da renda pode assumir várias formas, conforme nos diz Giuliano Conte. Pode ser derivada do trabalho direto do servo para o senhor feudal, isto é, os produtores trabalham parte de sua jornada de trabalho na porção de terra que thes cabe para seu sustento e subsistência e outra parte dessa jornada na teira do senhor, isto é: sobretrabalho. Uma segunda maneira é a entrega do sobreproduto ná forma de produtos da terra e de produtos de manufatura artesanal familiar. Nesse sistema a familia começa a aparecer como um núcleo produtivo autônomo e auto-suficiente. Para Conte esta primeira autonomia econômica seria um germe de transformação que possibilitaria "o aparecimento de um processo de diferenciação econômica do campesinato, que passará de servo da gleba em tributário do senhor, mais tarde em rendeiro e, finalmente, em capitalista, por um lado, e, por outro, em proletário totalmente desenraizado das condiçōes materiais de sua existência". Mas este processo, para se efetivar, "exige o desenvolvimento do mercado e a transformação do sobreproduto em dinheiro, através 
do comércio, como sua base real"' 2 Portanto a última forma em que surge a transferência do excedente sob o feudalismo é a forma monetária, em que o produtor vai ele próprio ao mercado e transforma seu sobreproduto em dinheiro, que entrega ao senhor. Esta evolução que se verificou vai criar as condições para a desagregação do próprio sistema feudal; é claro que existem outras condições e causas do processo de dissolução do feudalismo, mas que não cabe aqui examinar.

Conforme bem caracteriza Samir Amin, as formações sociais são estruturas concretas compostas de vários modos de produção, sob a dominância de um modo de produção específico que se articula com os outros modos de produção existentes. $O$ modo de produção mercantil simples nunca foi um modo de produção dominante, apenas existiu como uma esfera dentro de uma formação social sob o domínio de outro modo de produção (comunitário ou tributário), e se caracteriza pela produção de mercadorias simples, para troca, onde os produtores ainda são proprietários dos meios de prouçã̃o e têm por objetivo final o consumo. Como nos diz Sweezy: "Na produção de mercadorias simples, o produtor vende seu produto a firn de adquirir outros, que satisfaçam suas necessidades. Começa com Mercadorias, transforma-as em Dinheiro, e este novamente em Mercadorias. As mercadorias constituem o começo e o fim da transação, que encontra sua justificativa no fato de que as mercadorias adquiridas são qualitativamente diferentes daquelas que são vendidas." 3

Como vimos, em todos os modos de produção pré-capitalista a criação e a utilização do excedente é clara e límpida. Neste quadro institucional, para que os produtores aceitem esta expropriação forçada de seu sobretrabalho, é precisc que a concebam como essencial para a sobrevivência da própria ordem social na qual vivem, e é neste sentido que se vislumbra o importante papel desempenhado pela forma religiosa, que toma a instância político-ideológica, ciominando a vida social.

Quando analisamos as formações capitalistas vemos que são todas caracterizadas pela dominância do modo de produção capitalista. Este modo de produção implica a separação entre os produtores e os meios de produção. Agora, de um lado temos a proprie-

2 - CONTE, Giuliano. Da Crise do Feudalismo ao Nascimento do Capitalismo. Lisboa, Ed. Presença, 1979, p. 20.

3-SWEEZY, Paul M. Teoria do Desenvolvimento Capitalista. Rio de Janeiro, Zahar Editores, 1982, p. 86. 
däde dos meios de produção nas mãos de um grupo específico de pessoas, os capitalistas; e de outro os trabalhadores livres e desprovidos de meios de produção, portanto da possibilidade de produzirem para a sua própria subsistência, o que os leva a vender sua capacidade de trabalho a fim de garantir sua sobrevivencia e de sua família.

O capitalismo implica a produção de mercadorias, sendo este o elemento mais simples, mas que constitui a própria essência do sistema. E é a partir da mercadoria que Marx vai anal isar o sistema capitalista de produção: "pressupõe antes de tudo circulação de mercadorias", 4 e "logo então, quando o trabalho assalariado constitui sua base, a produção de mercadorias se impõe forçosamente à sociedade em seu conjunto". 5 a força de trabalho se apresenta aqui como uma mercadoria específica e especial, pois só ela é capaz de gerar valor.

O importante a destacar é que a relação agora não é mais entre indivíduos ou homens, mas sim entre coisas. Os produtores só se relacionam através das mercadorias e da sua troca.

Para Marx "o caráter misteriorso da forma mercadoria esbarra portanto, pura e simplesmente, em que projeta ante os homens o caráter social do trabalho destes como se fosse um caráter material dos próprios produtos de seu trabalho, um dom natural social destes objetos e como se, portanto, a relação social que intermedia entre os produtores e o trabalho coletivo da sociedade fosse uma relação social estabelecida entre os mesmos objetos, à margem de seus produtores (...) A isto é que eu chamo o fetichismo sob o qual se apresentam os produtos do trabalho (...)" 6

Enquanto que no feudalismo a teologia justificava e garantia a exploração explícita, no capitalismo a criação e apropriação do excedente é mescarada e se dá pela via econômica : agora o capital é considerado produtivo, tal como o trabalho, e o lucro aparece, assim, como sua justa remuneração.

Nesta sociedade capitalista, a criação do sobreproduto é o resultado e o objetivo do próprio sisterna, inerente às suas características básicas, e diferentemente dcs outros modos de produçăo, independente da vontade e da ação dos indivíduos, tendo seu fundamento na base econômica. O trabalhador, agora desprovido dos

4 - MARX, Karl. El Capital. México, Fondo de Cultura Económica, 1946. Tomo III, p. 355 .

5 - IBID, Tomo I, p. 616.

$6-$ IBID, TCMo !, p. 37-38 
meios de produção, vende no mercado a sua capacidade de trabatho ao capitalista, estabelecendo-se, aparentemente, uma troca de equivalentes. Portanto, aparentemente o indivíduo está liberto dos laços de servidão e de qualquer forma de coação e domínio, e já não há evidência clara de apropriação explícita de um sobreproduto de uma classe por outra. Em uma sociedade onde todos são iguais aos olhos da lei, onde não há coerção e sim liberdade, como explicar a exploração? A partir desta contradição é que surge a questão do valor.

\section{3 - BREVE HISTORICO DO PENSAMENTO ECONOMICO QUANTO A QUESTAOO DO VALOR}

O início de uma sistematização da ciência econômica é o resultado das próprias transformações econômicas acima descritas, que levaram à evolução do sistema capitalista.

E relevante a contribuição dos fisiocratas, pois são eles os primeiros a levantarem a questão do excedente econômico, para eles - resultado físico do produto líquido da agricultura. A questão do excedente é determinada fisicamente, sendo que só a agricultura é uma atividade produtiva, já que só é produtivo um trabalho que gere excedente e só a agricultura gera excedente. A produtividade depende, portanto, da produtividade da terra. E o excedente é o que sobra depois de deduzido o salário do trabalhador agrícola ( $n$ ivel de subsistência) e que é apropriado pelo proprietário da terra. "Tal concepção levou os fisiocratas a estabelecer uma identificação implícita entre custo e valor, de modo que o valor assumia aqui sua expressão puramente material, tangível." 7

E através da crítica das idéias fisiocráticas que Adam Smith vai desenvolver a sua teoria econômica, tendo como interesse primordial a questão do lucro, e portanto do excedente. Para ele, há produção de excedente em todos os setores da economia e aparece, assim, a necessidade de uma teoria do valor para determinar a origem e o destino do excedente e do lucro.

Adam Smith é o primeiro a considerar o trabalho como fonte e medida do valor. $O$ trabalho é que é produtivo. $E$ de que depende a produtividade do trabalho? Da divisão social do trabalho, ou

7 - BELLUZZO, Luiz Gonzaga de Mello. Valor e Capitalismo. São Paulo, Brasiliense, 1980, p. 21 
seja, da atribulação de atividades específicas, de operações relativamente pequenas aos trabalhadores separadamente. $E$ esta divisão é que vai determinar a posição dos indivíduos na sociedade e vai lhes impor a necessidade de troca.

Dada a divisão social do trabalho, o valor do trabalho é proporcional à quantidade de mercadorias que o trabalhador pode adquirir. Por conseguinte, temos uma troca de quantidades iguais, de equivalentes materializados em trabalhos iguais, se realizando de acordo com seu valor. "Neste sentido, o valor do trabalho é igual ao valor do produto do trabalho, ou, em outras palavras, o valor das mercadorias é proporcional à quantidade de trabalho vivo que com elas se possa comprar ou 'comandar."

Quando Adam Smith passa da análise da sociedade simples, em que os produtores são ao mesmo tempo possuidores e vendedores de mercadorias, para a sociedade capitalista, surgem dificuldades. No primeiro caso o trabalho comandado e o trabalho contido se igualavam, agora no capitalismo esta igualdade já não se veri. fica, e o trabalho comandado deixa de ser trabalho contido. $O$ que Adam Smith não percebeu é a característica específica da mercadoria força de trabalho no capitalismo, que é capaz de produzir um valor maior do que o seu próprio valor. Agora o valor do trabaIho (salário) já não é mais equivalente ao valor do produto do trabalho. Para resolver seu impasse, Smith coloca que a origem do lucro não está no processo de troca de mercadorias, mas no fato de o capitalista vender, sem pagar, uma parte do produto do trabalhador. Comete um erro, e retrocede ao afirmar que "o salário, o lucro e a renda da teria são as três fontes originárias de toda a renda e de todo o vâior de troca". ${ }^{9}$ Pcis antes havia postulado apenas o trabalho como fonte de valor. Assim, confunde preço com valor e cai em uma tautologia, pois pretende explicar preços através de preços.

Ricardo constrói sua obra com o objetivo de descrever os mecanismos que determinam a taxa de lucro, que é o que move a economia capitalista. Para ele a taxa de lucro geral depende da taxa de lucro da agricultura, sendo que o valor continua sendo determinado pelo trabalho contido. Analisa a formação da renda diferencial proveniente de terras de fertilidades diferentes, o que leva à queda na taxa de lucro e ao estado estacionário.

$8-$ IBID, p. 25

9 - SMITH, Adam. Da Riqueza das Naçôes. Lisboa, Fundação Calouste Gulbenkian, 1980 , p. 52. 
Para Ricardo a medida de valor é o tempo de trabalho contido nas mercadorias, e que vai determinar as relaçóes de troca na sociedade capitalista. Mas abandona a noção de Adam Smith de "trabalho comandado". Ao mesmo tempo, se dá conta de que há um momento em que é burlada a lei do valor, em que a troca não é de equivalentes: a quantidade que o trabalhador recebe de mercadorias como salário é menor que a quantidade de mercadorias que produz. Mas não resolve este problema, deixando-o de lado. Mas em outro sentido, foi adiante, e através da lei da população de Malthus, foi capaz de determinar o que chama de "valor do traba"ho", isto é, tempo de trabalho incorporado nos meios de subsistência que permitem a subsistência do trabalhador e sua familia.

As mercadorias produzidas na mesma circunstância (relação entre capital fixo e capital circulante) têm o mesmo valor. E o lucro aparece como um resíduo, após a dedução do salário; é portanto um sobretrabalho.

Belluzzo coloca bem o problema da teoria do valor de Ricardo:

“Se, por um lado, a noção de lucro como 'excedente' sobre o consumo necessário à produção é compat1vel com o procedimento de Ricardo relativo à determinação dos salários, de outra parte a consecução desse resultado só é possível mediante a supressão silenciosa do princípio da equivalência, no momento crucial do intercâmbio entre capital e traba!ho. Isso significa que não apenas o 'valor do trabalho', senão, igualmente, o surgimento do lucro como renda do capital, são explicados, independentemente da teoria do valor, ou melhor, a despeito dela." 10

A partir dos avanços e dificuldades apresentados nos trabaIhos de Smith e Ricardo é que Marx vai realizar uma reflexão critica, principalmente sobre os conceitos de trabalho necessários e de trabalho contido, no sentido de resolver os impasses apresentados.

\section{4 - TEORIA MARXISTA DO VALOR}

Como foi visto, na sociedade capitalista todos os individuos se apresentam em condições de igualdade e se defrontam no mercado como compradores ou vendedores de mercadorias. Nesse mercado,

10 - BELLUZZO, op. cit., p. 43. 
todas as trocas são trocas de equivalentes e não há evidência clara, conseqüentemente, de nenhum desvio neste nivel.

Uma mercadoria é por um lado uma coisa útil, pois satisfaz as necessidades humanas, e neste sentido se caracteriza como valor de uso, estando condicionada por suas qualidades materiais; e por outro lado forma o meio material do valor de troca. Como se lê no primeiro capítulo d' O Capital "( . . .) se prescindirmos do valor de uso das mercadorias, estas só conservam uma qualidade: a de serem produtos do trabalho. Mas não produtos de um trabalho real $\mathrm{e}$ concreto. Ao prescindir de seu valor de uso, prescindimos também dos elementos materiais e das formas que os convertem em tal valor de uso." 11 Assim, abstraindo suas formas e qualidades que thes dão valor de uso, também desaparecem as diferentes formas concretas desse trabalho que se corporifica na mercadoria. Por conseguinte, os diferentes trabalhos já não se distinguem entre si, mas se tornam trabalho humano abstrato.

E o que determina o valor das mercadorias? O tempo de trabalho requerido para produzi-las sob condições normais de produção, isto é, conforme a técnica e a intensidade de trabalho prevalecente em uma dada sociedade. Assim, as mercadorias, nas quais estão contidas as mesmas quantidades de trabalho, que são produzidas no mesmo tempo de trabalho, têm o mesmo valor. Consolicia. se aqui a própria lei do valor, que regula e governa as relações de troca das mercadorias: as trocas são proporcionais ao trabalho socialmente necessário incorporado nelas; as mercadorias são trocadas de acordo com seu valor!

E aqui que se coloca a importância da solução que Marx dá à questão do valor. Para ele a força de trabalho também é uma mercadoria, não apenas uma mercadoria qualquer, mas uma mercadoria especial, já que é capaz de criar valor.

Examinemos isso mais de perto.

E imprescindível, para esclarecer esta questão, distinguir entre trabailho e força de trabalho. A força de trabalho é o que o trabalhador vende ao capitalista, é o seu valor de troca, enquanto o trabalho em si é o valor de uso que o capitalista adquire, isto é, a quantidade de trabalho que o operário, o portador da força de trabalho, é capaz de fornecer dentro do processo produtivo.

Portanto, a troca entre a força de trabalho e o capital apresenta uma especificidade importante e primordial. O capital ista com. pra a força de trabalho por seu valor, sendo o seu valor determina-

11 - Marx, op. cit., Tomo 1, p. 5. 
do pelo tempo de trabalho necessário para sua reprodução, tempo de trabalho necessário para produzir os meios de subsistência do trabalhador, ou o valor desses meios. O que se verifica então é uma troca de equivalentes, e o capital ista paga ao trabalhador o valor de sua força de trabalho. E a lei do valor é satisfeita, pois em nenhum momento são infringidas as leis de troca de mercadorias. No entanto, a mercadoria força de trabalho que o capitalista comprou possui a capacidade especial de criar um valor superior ao valor de sua força de trabalho e o capitalista faz com esta mercadoria o que faz todo comprador: consumir seu valor de uso. ${ }^{12}$ Dentro do processo produtivo, pois, temos o tempo adicional de trabalho, pelo qual o trabalhador não recebe nenhum equivalente, e o produto desta parcela de trabalho é o que Marx denomina de mais-valia e constitui a base do lucro capitalista.

$\mathrm{Na}$ esfera da circulação, como vimos, não há criação de valor, pois o que se realiza aqui é a troca de equivalentes, e mesmo que não se troquem equivalentes, estas diferenças se contrabalançam entre si e não há criação de mais-valia. Como ressalta Marx:

"O que de um lado aparece como mais-valia, é do outro menos-valia; o que de lima parte representa um mais, representa da outra um menos (. . .) E evidente que a soma dos valores circulantes não aumenta, nem pode aumentar, por muitas trocas que se operem em sua distribuição (.. . . A A classe capitalista de um país não pode enganar a si mesma em bloco". 13

Conclui-se então que o processo de valorização acontece na esfera da produção, pelos mecanismos apontados acima, se realizando na circulação. Dependendo portanto da existência de uma outra "mercadoria particular: o dinheiro cujo valor de uso consiste precisamente em seu valor de troca: o dinheiro é $\checkmark$ valor de troca tornado autônomo". ${ }^{14}$

Marx conduz então a análise do valor, partindo das mercadorias até chegar ao capital. Para ele, o valor, que define as relações de troca entra as mercadorias como expressão das relações sociais, deve ser definido antes do capital. Isto não implica referência a uma sociedade mercantil não-capitalista. Para que o capital nasça e se desenvolva é preciso, primeiro, a produção de mercadorias, mesmo como um modo de produção de mercadorias simples.

12 - IBID, Tomo I,p. 145.

13 - IBID, Tomo I, p. 117

14 - 14 - NAPOLEONI, Cláudio. O valor na Ciência Econômica. Lisboa, Editor ial Pre. sença, 1977, p. 59 . 
E a essếncia do capitälismo baseia-se então no impulso incessante dós 'cápital istas no sentido de aumentarem seu capital. Para tanto "é preciso aumentar constantemente os lucros, isto é, a relação entre a mais-valia e o capital utilizado na produção, o que leva a uma exploração cada vez maior da classe trabalhadora. Em segundo lugar, é preciso acumular a maior parte possível deste lucro. Marx ressalta então as contradições inerentes ao capital ismo e que podem levar à sua destruição, através da sua lei da tendência da queda da taxa de lucro.

As eloqüentes palavras de Paula intensificam o entendimento deste processo: "O capital, coleção de mercadorias, é irreconhecível enquanto sendo feito da mesma matéria que a mercadoria. A realidade do capital parece escapar ao contingencial, ao prosaico, à dimensão valor de uso da mercadoria. O capital parece potência indomável, de tudo capaz, invulnerável, seu movimento parece irresistível. Entretanto, periodicamente estalam as juntas e o gigante desaba com todo n peso de sua pujança. É a crise."15

\section{5 - VIGENCIA E LIMITES DA LEI DO VALOR}

A lei do valor na sociedade capitalista é responsável pelo equilíbrio de todo o sistema, como relações entre as diferentes categorias que o compõem e que representam as relações entre os indivíduos desse sistema. Examinando estas relações, pode-se ver como a lei do valor regula, espontaneamente, as relações de produção $e$ distribuição, se considerarmos uma economia capitalista de livre concorrência, onde exista plena liberdade de circulação das diferentes categorias de mercadorias.

Começando pela relação Salário e mais-valia, vernos que esta relação representa a própria essência do sistema, isto é, a repartição do produto do trabalho entre trabalhadores e capita!istas. Já o lucro constitui uma relação entre os próprios capitalistas, que se movem sempre em direção a sua maximização (não no sentido neoclássico, é clarol e por conseguinte garantem o funcionamento do mecanismo de igualização das taxas de lucro entre os diferentes ramos, lévando a um mecanismo secundário, porque resultado do primeiro, distribuição de trabalho e meios de produção e, conseqüentemente, à organização da produção como um todo. A cate-

15 - Paula, op cit., p. 129. 
goria préco rpor suavez rias e indivíduos deste sistema, na forma de uma relação de produçåo, devido aos mecanismos de afastamento entre preço e valor e a conseqüente redistribuição das forças produtivas entre os diferentes ramos da economia; e sob a forma de uma relaçăo de repartição entre os grupos sociais, na medida em que "o nível dos preços determina o dos fluxos dos valores que passam das mãos de certos grupos de homens para outros". 16

O valor resume assim estas relaçóes, e as interliga e unifica, e seu movimento é que determina o próprio movimento do capital, a distribuição do capital e do trabalho, e a própria reprodução do sistema. Mas para que a lei do valor tenha vigência plena, é necessário que se cumpram algumas exigências importantes, a saber:liberdade total de circulação de mercadorias; existência de mercado de trabalho livre; mínima intervenção e participação do Estado; inexistência de mecanismos de regulamentação de preços e plena liberdade de concorrência. ${ }^{17} \mathrm{E}$ exatamente neste sentido que a lei do valor encontra barreiras no próprio desenvolvimento capitalista, que comanda, e que teve como resultado o capitalismo monopolista. Assim é que limitou-se a concorrência pela concentração do capital, pela formidável expansão do capital financeiro, pelo aparecimento de grándes e poderosos grupos produtivos, cartéis e sindicatos, e pelo fortalecimento também ao Estado centralizador, sendo que as tendências monopolistas estendem-se além das fronteiras nacionais, englobando todo o mundo capitalista e até mesmo os países socialistâs, na medida em que estes se relacionam com o primeiro.

Enfim, dentro mesmo do capitalismo, o desaparecimento da liberdade de concorrência, resultado do próprio processo de acumulação de capital e de seus mecanismos intrínsecos, limita a lei do valor, que encorıtra então uma série de obstáculos ao seu pleno funcionamento regulador. Agora seus mecanismos são parcialmente substiturdos por outras formas, controladas pelo capital monopolista e pela ação comprometida do Estado.

Uma das manifestações claras deste tipo de movimento é quanto à regulação dos preços e valores, tanto de produtos quanto de insumos, incluindo-se aí a própria forma de trabalho. Dada esta discrepância entre preços e valores, apresenta-se a impossibilidade

16 - PREOBRAJENSKY. Eugênio. A Nova Económica. Rio de Janeiro, Paz e Terra, 1979, p. 169.

17 - IBID,p. 171 
da igualização da taxa de lucro, em favor, é claro, dos capitaisimá is concentrados e poderosos. A fixação dos preços pelo :Estado, respondendo aos interesses do capital monopolista, é, portanto, também um exemplo do enfraquecimento da lei do valor, pois é o Estado agora que regula a própria exploração e a distribuição da maisvalia.

Examinemos agora a vigência da lei do valor no socialismo.

Conforme bem diz Roman Rosdolsky, dentro do marco teórico marxista, do método materialista dialético de Marx, que procura entender toda manifestação social no fluxo de seu nascimento, existência e explicação, podemos observar as condições do próprio movimento capitalista como abolindo-se a si mesmas e como condicionando e possibilitando o ordenamento de uma nova sociedade, a sociedade socialista. ${ }^{18}$

Mas é preciso distinguir a passagem do capitalismo para o socialismo, da passagem do feudalismo para o capitalismo, já analisada, superficialmente, neste trabalho. Como vimos, o surgimento do capitalismo encontra suas raízes na própria desagregação do sistema feudal, sendo que a acumulação primitiva do capital acontece justamente numa época em que politicamente prevalece o absolutismo, e economicamente ainda imperam as relações feudais e a produção mercantil simples. O socialismo, pelo contrário, não pode conviver e se desenvolver aos poucos dentro do sistema capitalista. Sua única possibilidade é a revolução social e a tomada do poder e dos meios de produção pelo proletariado, com a ruptura total do antigo sistema. Neste sentido, é claro que quanto mais desenvolvido o próprio modo de produção capital ista que antecede o socialismo, que inclusive pressupõe uma acumulação de capital prévia mínima, maior será a sua herança e melhores as suas cond:ções de desenvolvimento e consolidaçao.

Quando Marx examina a questão do desenvolvimento tecnológico vê a possibilidade de que, no socialismo, os operários possam ser transformados de meros apêndices do processo produtivo em seus verdadeiros controladores. Examina a questão do tempo de trabalho e diz que "por um lado o tempo de trabalho necessá rio encontrará sua medida nas necessidades do indivíduo social e por outro o desenvolvimento da força produtiva social será tão rápido que, ainda que agora a produção se calcule em função da riqueza comum, crescerá o tempo disponível de todos. Já que a riqueza real é a força produtiva desenvolvida de todos os indivíduos.

18 - ROSOOLSKY, Roman-Genesis y Estructura de El Capital de Marx. México, Siglo Veintiuno Editores, 1978. 
Já não é então, de modo algum, o tempo de trabalho, a medida da riqueza, senão o tempo disponível. $O$ tempo de trabalho como medida da riqueza póe a riqueza mesma como fundada sobre a pobre. za e ao tempo disponível como existente na e em virtude da antitese com o tempo de mais trabalho, ou bem põe todo o tempo de um indivíduo como tempo de trabalho e conseqüentemente o degrada a mero trabalhador, o resumo no trabalho." 19

Em uma ordem verdadeiramente socialista é evidente que o trabalho não desaparece como categoria social. O que desaparece é o sobretrabalho ou o mais-trabalho, que no capitalismo significa a própria fonte de exploração da maioria por parte de uma minoria. O trabalho, para Marx, como condição da própria vida humana, é eterno e comum a qualquer tipo de sociedade.

Como se pode analisar, dentro desta perspectiva, a validade da lei do valor no socialismo?

Para Roman Rosdolsky, como a lei do valor era considerada pelos fundadores do marxismo como a expressão mais concreta e ampla da escravização dos produtores por parte de seu próprio produto, de modo algum poderá estender-se a uma sociedade socialista a vigência da lei do valor.

No socialismo todo o trabalho é trabalho social. Não existe produto particular, produzido para a troca, e pelo contrário, sua produção não tem valor de troca. Assim, em vez de uma divisão social do trabalho, determinada exatamente pelos valores de troca das mercadorias e sua subseqüente relação no mercado, a organização do trabalho terá como objetivo a produção social comunitária e a sua distribuição entre os indivíduos conforme a porção que lhes cabe no consumo coletivo. Desta maneira, a medição do tempo de trabalho, base da própria teoria do valor, só serve como medida que possibilite a planificação central da produção e da distribuição. É claro que poderá haver um sobretrabalho, mas no sentido de possibilitar a acumulação necessária ao desenvolvimento produtivo, que será feita em benefício da coletividade como um todo; poderia assim ser considerado, na verdade, como um trabaIho necessário e não um trabalho excedente. Portanto pode-se dizer, e deve-se inclusive salientar, que no socialismo existe um sobretrabalho e um excedente; entretanto, a diferença essencial é que este excedente agora é social a priori.

Pode-se concluir, por conseguinte, que a lei do valor no socialismo perde toda a sua significação. Não é mais o mercado que regula a produção e a distribuição das mercadorias e da riqueza, é

19 - IBID, pp 595-596. 
a própria sociedade que conscientemente assume o controle de seu destino como uma coletividade realmente sem classes. A medida do tempo de trabalho, então, serve apenas como ferramenta para a planificação central que assume a maioria das funçoes reguladoras, que no capitalismo são exercidas pela lei do valor. $E$ além do mais, e inclusive de importância fundamental, como desapareceram, verdadeiramente agora, as diferenças de classes, não há mais exploração para ser revelada e desmificada, e seu principal objetivo (da lei do valor) acaba de morrer.

Estas conclusões representam uma faceta puramente teórica da questão. Podemos, de alguma maneira, fazer uma comparação com a realidade, para ver os verdadeiros limites da vigência da lei do valor nas denominadas democracias populares? Com este propósito pode-se examinar o exemplo da União Soviética. Para Eugênio Preobrajensky, o essencial na consolidação de uma revolução anticapitalista em um país industrialmente atrasado é a luta, incessante, entre a lei do valor, herdada do passado capitalists, e a lei da acumiłlação socialista, que resume o princípio da planificação socialista centralizada. Estas duas leis são diametrialmente opostas e se chocam constantemente no desenvolvimento da sociedade socia. lista, sendo que a consolidação do socialismo verdadeiro depende do resultado desta luta.

O principal motor da economia soviética é a lei fundamental da acumulação socialista primitiva que é "a soma de todas as tendências conscientes e semi-espontâneas da economia estatal que estão orientadas para a ampliação e reforçamento da organização coletiva do trabalho na economia soviética". 20 Esta lei é que "controla: o volume do subproduto subtraído da economia privada; o nível de salários da economia estatal; a política de preços; a regulação do comércio externo e interno;o sistema alfạndegário; a política de crédito; a elaboração do orçamento; os planos de importação, etc." $(. .)^{21}$

Mas esta é apenas uma parte da economia soviética, que também é composta por uma econọmia privada, na esfera da produção mercantil simples. Portanto, na União Soviética observa-se a coexistência destes dois sistemas econômicos diferentes e antagônicos concomitantemente, e que se relacionam entre si. Assim, a economia estata/ representa os interesses socialistas e é controlada pela lei fundamental da acumulação socialista primitiva, enquanto que a

20 - PREOBRAJENSKY, op. cit , p. 165.

21 - IBID, p. 166. 
parcela da economia privada depende da açào da lei do valor. E é claro que não são departamentos estanques e portanto as duas leis se confrontam e se estendem uma sobre o palco da outra, o que caracteriza a luta entre elas. O sistema econômico soviético pode ser considerado, assim, como um sistema econômico mercantil-socialista.

Como salienta Eugênio Preobrajensky:

"A tei da Acumulação Socialista está limitada pela "democracia" da economia mercantil, com suas tendências de desenvolvimento e seus próprios métodos de regulação. A economia mercantil é limitada, englobada e, se quisermos, comprimida pela lei da acumulação socialista, pelas leis do desenvolvimento do corpo socialista que lhe é estranho. Deste modo, nossa economia, sem ser ainda socialista, já não é puramente mercantil." 22

Podemos concluir, por conseguinte, que no momento em que a lei da acumulação socialista vencer a luta, a lei do valor desaparecerá juntamente com a parcela da economia privada que representa. Neste sentido, confirmam-se as conclusões anteriores, de que no socialismo a lei do valor encontra barreiras intransponíveis e acabará por desaparecer completamente.

\section{$6-$ CONCLUSOES}

Depois desta caminhada pelo passado e pelo presente da lei do valor, espera-se ter conseguido estabelecer e deixar clarc o seu lugar e sua pretensão: retirar e desvendar a máscara que esconde a exploração no sistema econômico capitalista, exercendo a função de mecanismo regulador tanto do sistema produtivo como da distribuição através dos mecanismos de mercado; e seus limites, que aparecem no desenvolvimento do capitalismo e no socialismo.

Mas em que meơida é a própria lei do valcr que prepara o cenário de seu desaparecimento?

Como foi visto, para que a lei do valor possa desempenhar seu papel plenamente, é preciso que existam condições de livre concorrência. Mas sabemos que a livre concorrência, no sistema capitalista, com sua incessante luta competitiva, devido à sua mola mestra, que é a contínua busca de maior lucro e a busca da acumulação de

$22-1810$, p. 156. 
capital, leva à superprodução de mercadorias, à crise propriamente dita. E como o capitalismo resolve suas crises? Para que o sistema saia da crise é preciso que se realize a "queima" do capital excedente, da capacidade ociosa então criada, e então acontece a ruína de uma parcela do capital, a mais frágil, em benefício do fortalecimento de outra parcela do capital, a mais forte, e que assim fica ainda mais poderosa. Descrevemos, então, uma tendência para a concentração do capital, e este é o caminho do capitalismo monopolista. E neste movimento, com estas transformações, que a lei do valor começa a sentir seus próprios limites.

Assim, a lei do valor ao comandar a luta competitiva implica a própria restrição da competição e a concentração e centralização do capital, implicando portanto a criação das condições de seu próprio bloqueio e destruição.

\section{REFERENCIAS BIBL!OGRÁFICAS}

BE LL.UZZO, Luiz Gonzaga de Mello. Valor e Capitalismo. São Paulo, Brasiliense, 1980.

CONTE, Giuliano. Da Crise do Feudalismo ao NAscimento do Capitalismo. Lisboa, Ed. Presença, 1979.

DOBB, Maurice. 4 Evolução do Capitalismo. Rio de Janeiro, Zahar Editores, 1974.

MARX, Karl. El Capital. México, Fondo de Cultura Econômica, 1946.

NAPOLEONI, Cláudio. O Valor na Ciéncia Económica. Lisboa, Ed. Presença, 1977.

PAULA, João Antônio de. "Ensaio sobre a atualidade da Lei do Valor". In: Revista de Economia Política, São Paulo, Brasiliense, Vol 4, no 2, abril-junho de 1984.

PREOBRAJENSKY, Eugênio. A Nova Económica. Rio de Janeiro, Paz e Terra, 1979.

ROSDOLSKY, Roman. Génesis y Estructura de El Capital de Marx (estudios sobre los Grundisse). México, Siglo Veintiuno Editores, 1978.

SMITH, Adam. Da Riqueza das Nações. Lisboa, Fundação Calauste Gulbenkian, 1980.

SWEEZY, Paul M. Teoria do Desenvolvimento Capitalista. Rio de Janeiro, Zahar Editores, 1982. 